\title{
Verrucous lepromatous leprosy: a rare form of presentation - Report on two cases*
}

\author{
Marcelo Zanolli Medeiros ${ }^{1}$ \\ Luiz Carlos Takita ${ }^{1}$ \\ Aline Blanco Barbosa
}

\author{
Gunter Hans Filho ${ }^{1}$ \\ Carolina Faria Santos Vicari ${ }^{1,2}$ \\ Daíne Vargas Couto ${ }^{1}$
}

Abstract: Leprosy skin lesions are described as hypochromic or erythematous macules, pale erythematous or reddish-brown plaques, papules, nodules, and diffuse cutaneous infiltration, depending on the clinical form of the disease. They may be accompanied by hypo or anesthesia, alopecia, and hypo or anhidrosis. Verrucous lesions are now quite uncommon in leprosy. The literature is sparse, with only 25 reported cases of this association, especially in the lepromatous pole of the disease. This work is a report on two cases of lepromatous leprosy of long evolution, coursing with vegetant verrucous lesions.

Keywords: Infectious dermatopathies; leprosy; multibacillary leprosy; lepromatous leprosy; Mycobacterium leprae.

\section{INTRODUCTION}

Leprosy is a chronic granulomatous infection caused by Mycobacterium leprae, an intracytoplasmic parasite of macrophages and Schwann cells, with a predilection primarily for peripheral nerves, and secondarily for the skin and internal organs. Disease progression is slow and its clinical form depends on specific host immunity, ranging from the higher resistance pole (tuberculoid), the lower resistance pole (lepromatous) and spectra of the disease with intermediate immunity resistance (borderline leprosy). ${ }^{1,2}$

Leprosy skin lesions are described as hypochromic or erythematous macules, pale erythematous or reddish-brown plaques, papules, nodules, or diffuse cutaneous infiltration, depending on the clinical form of the disease. They may be accompanied by hypo or anesthesia, alopecia, and hypo or anhidrosis. ${ }^{1,2}$

Verrucous lesions are now quite uncommon in leprosy. The literature is sparse, with only 25 reported cases of this association, especially in the lepromatous pole of the disease..$^{3-9}$

This work is a report on two cases of lepromatous leprosy of long evolution, coursing with vegetant verrucous lesions.

\section{CASE REPORTS}

CASE 1: Female, 80 years old, presented verrucous plaques on both feet, with recurrent impetiginization associated with burning pain, for 4 years. Referred dysphagia with progressive weight loss for 15 years, "dropped nose" for 10 years and bilateral amaurosis for 8 years. Showed madarosis, bilateral nasal collapse, no left eyeball and complete corneal opacity in the right eye, generalized cutaneous infiltration and vegetant verrucous plaques on feet and legs, associated with hard edema and dystrophic nails (Figures 1 and 2). Showed positive bacilloscopy and histopathological examination of vegetant lesion revealed pseudoepitheliomatous hyperplasia, dermal infiltrate composed of vacuolated histiocytes containing numerous globi of intact fast-acid bacilli, with no changes in lymphatic vessels (Figure 3). Search and culture for bacteria and fungi were negative in the fragment. There was improvement of the lesions after initiation of multidrug therapy.

CASE 2: Female, 41 years old, with vegetant verrucous lesions on the lower limbs, elbows and ears with mild madarosis and bilateral leg hypoesthesia for

\footnotetext{
Received on 09.06.2013.

Approved by the Advisory Board and accepted for publication on 05.08.2013.

* Work performed at the Departamento de Dermatologia do Hospital Universitário da Universidade Federal do Mato Grosso do Sul (UFMS) - Campo Grande (MS), Brazil. Conflict of interest: None

Financial funding: None

Universidade Federal de Mato Grosso do Sul (UFMS) - Campo Grande (MS), Brazil

São Julião Hospital - Campo Grande (MS), Brazil.

(C2014 by Anais Brasileiros de Dermatologia
} 


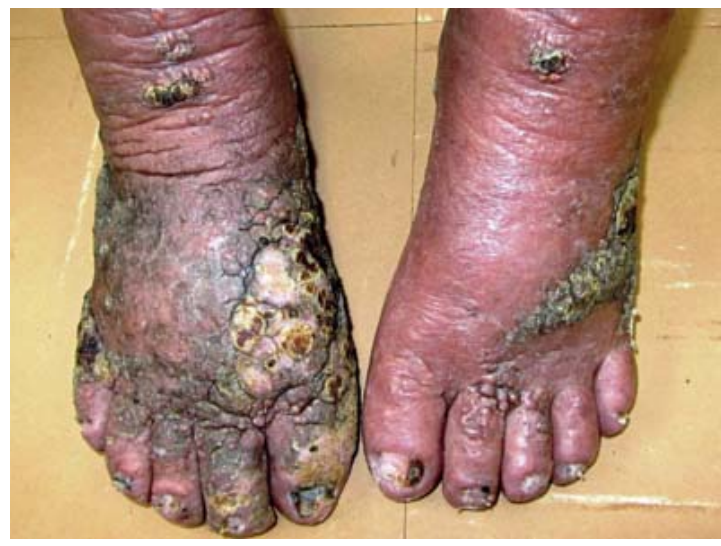

FIGURE 1:Verrucous plaques on the insteps of the feet and distal extremities of the legs

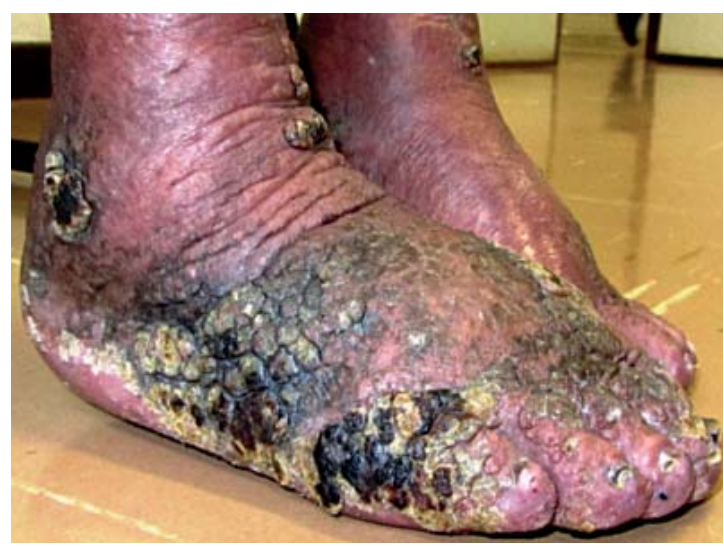

FIGURE 2: Verrucous plaques on the insteps of the feet and distal extremities of the legs (lateral view)

3 years (Figures 4 and 5). Bacilloscopy was highly positive. Histopathological examinarion of verrucous lesion showed pseudoepitheliomatous hyperplasia, hyperkeratosis, hypergranulosis and spinous layer with areas of acanthosis and atrophy, with no vacuolization and numerous fast-acid bacilli globi (Figure 6).

\section{DISCUSSION}

The first reference to verrucous lesions in leprosy was made by Babes at the 1st International Conference on Leprosy, in $1897 .{ }^{10}$ Souza-Araujo, in 1937, described three cases of lepromatous leprosy with verrucous lesions, which he denominated "leprous verrucous dermatitis ". In the same year, Baptista reported a similar case, using the name "verrucous leproma". ${ }^{6}$ In 1939, Braga described two cases, adopt-

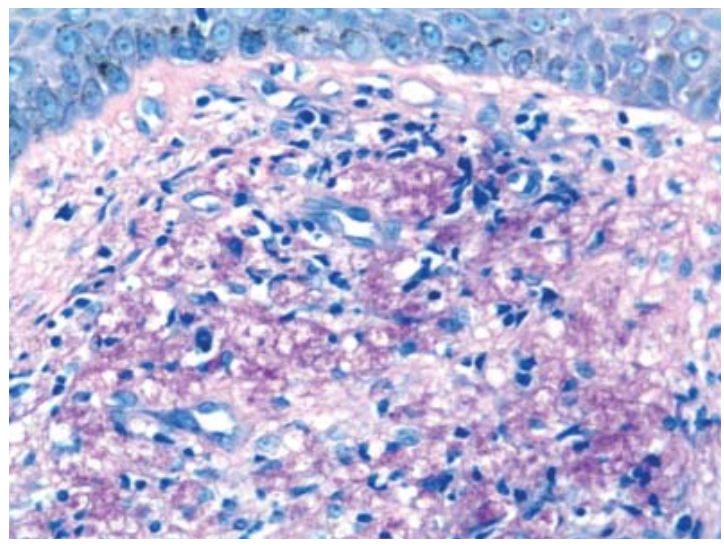

FIGURE 3: Dermal infiltrate composed of vacuolated histiocytes containing numerous globi of intact fast-acid bacilli, with no changes in lymphatic vessels (Fite-Faraco stain, 400X)

ing the same denomination as Baptista. ${ }^{7}$ All these patients had multibacillary leprosy with biopsies demonstrating large amounts of bacilli. In 1938, Ramos and Silva reported a case of pure neural leprosy that developed a verrucous plaque, the histopathological examination of which did not reveal the presence of bacilli, calling it "verrucous leprosy".9 In 1967, Pimenta, Mello and Campos described a case of tuberculoid leprosy reaction with warty lesions on the face. ${ }^{4}$ Patki described 15 cases and classified the lesions into three morphologic features: (i) lesions having finger-like projections, and resembling filiform warts, (ii) thick horn-like projections, and (iii) hyperkeratosis and deep transverse fissures corresponding to the skin creases on the anterior aspects of the ankles. ${ }^{8}$ Recently, Chang and Choi reported a lepromatous leprosy case with a verrucous plaque on the ankle, initially diagnosed as verrucous carcinoma that, histopathologically, showed an absence of epidermal atypia and presence of foamy histiocytes with great amount of acidfast bacilli globi. ${ }^{2}$ Finally, Yuchua-Guillen and Dofitas described a lepromatous leprosy patient with multiple verrucous nodules on the lower extremities that, after exhaustive investigation, had their etiology attributed to Mycobacterium leprae. ${ }^{3}$

Although there are few documented cases, vegetant verrucous lesions were relatively common in the past, in hospitalized patients with multibacillary leprosy who, through repeated episodes of erysipela, developed lymphatic impairment and elephantiasis, resulting in the appearance classically described as "mossy foot". However, in the reported cases, no changes were observed in lymphatic vessels upon histopathological examination and the location of the lesions in the second case does not support this diagnosis. 


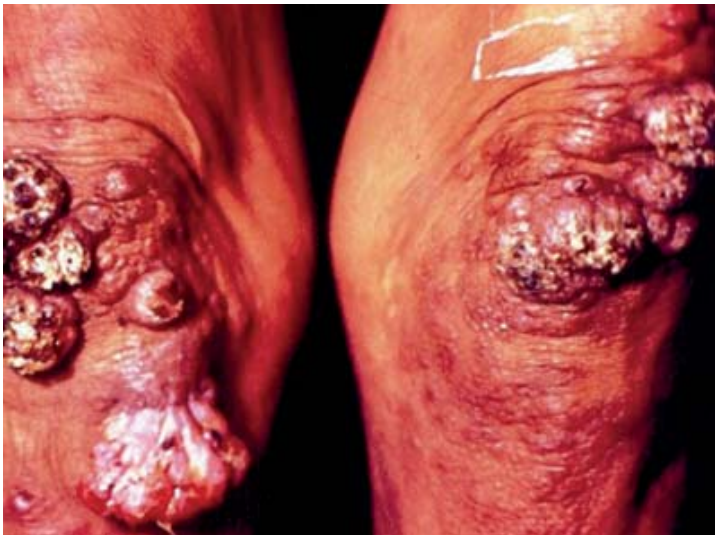

FigurE 4: Verrucous lesions on the knees

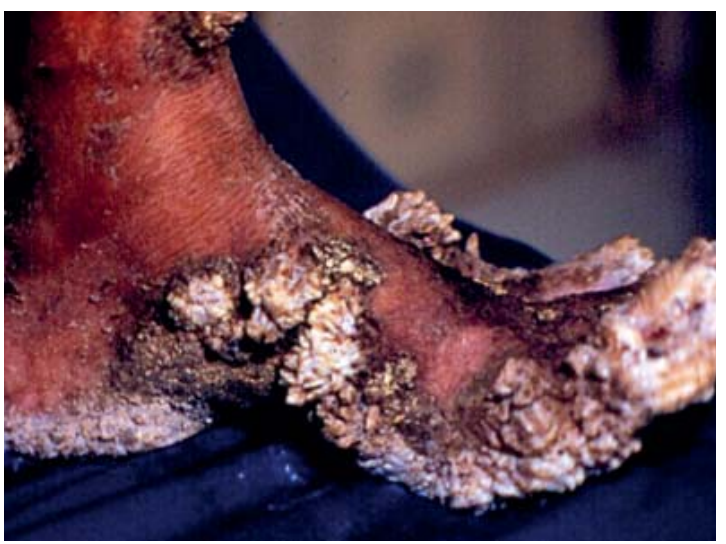

FIGURE 5: Verrucous lesions on the feet and distal third of the leg

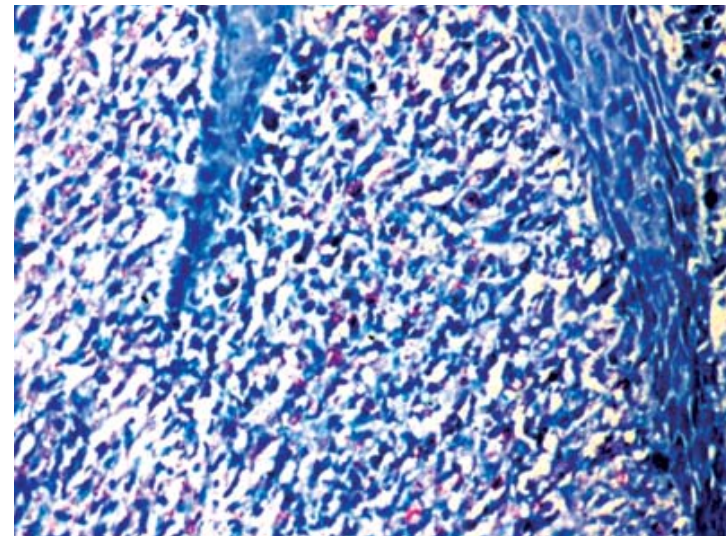

FIGURE 6: Epidermal hyperkeratosis with hypergranulosis and spinous layer with areas of acanthosis and atrophy, with no vacuolization and numerous fast-acid bacilli globi (Fite-Faraco stain, 400X)

Given the high endemicity of the infection in our region, leprosy should be included in the differential diagnosis of the verrucous syndrome, including paracoccidioidomycosis, leishmaniasis, sporotrichosis, cutaneous tuberculosis, and especially chromomycosis of long evolution.

It is concluded that leprosy may rarely manifest with verrucous lesions, especially in the lepromatous pole of the disease, suggesting advanced disease. ${ }^{2-5,7,8} \mathrm{It}$ is considered that the verrucous lesions are an uncommon cutaneous manifestation and not a distinct variant of the disease. ${ }^{6}$ Etiology is uncertain, but sensory loss, hypo or anhidrosis and inappropriate footwear, are factors that tend to be present. ${ }^{8} \square$ 


\section{REFERENCES}

1. Bolognia JL, Jorizzo JL, Rapini RP. Dermatology. 2nd ed. St Louis: Mosby; 2008.

2. Chang MM, Choi PCL. Lepromatous leprosy: a case simulating verrucous carcinoma. Hong Kong J Dermatol Venereol. 2012;20:77-81.

3. Yuchua-Guillen A, Dofitas BL. Atypical Hansen's disease presenting as florid verrucous plaques on the lower extremities: a case report. Int J Dermatol. 2012:51:697-701.

4. Pimenta WP, Mello ET, Campos J C P. Hanseníase tuberculóide reacional com lesões verrucosas. Rev Bras Leprol. 1967;35:47-52.

5. Souza-Araujo HC. Dermatite verrucosa leprótica - Estudo de três casos. Mem Inst 0 Cruz. 1937:32:311-20.

6. Baptista L. Um caso interessante de leproma verrucoso. Rev Bras Leprol. 1937;5:525-9.

7. Braga RP. Contribuição ao estudo das lesões verrucosas da lepra. Rev Bras Leprol. 1939;7:133-9.

8. Patki AH. Verrucous skin lesions on the legs of leprosy patients. Br J Dermatol. 1994:131:747-8.

9. Ramos e Silva J. Leprides verrucosas. An Bras Derm Sifilog. 1938;13:11-15

10. Babes V. Ueber die Histologie der Lepra. In: Mittheilungen und Verhandlungen der Internationalen Wissenschaftlichen Lepra-Conferenz zu Berlin im October 1897; 1897 Oct 11-16; Berlin, Germany. Berlin: August Hirschwald; 1897. v. 1, p. 152.
MAILING ADDRESS:

Marcelo Zanolli Medeiros

Av. Senador Filinto Muller, 355

Vila Ipiranga

79080-190 - Campo Grande - MS

Brazil

E-mail: zanolli_marcelo@hotmail.com

How to cite this article: Medeiros MZ, Hans-Filho G, Takita LC, Vicari CFS, Barbosa AB, Couto DV. Verrucous lepromatous leprosy: a rare form of presentation - Report on two cases. An Bras Dermatol. 2014;89(3):481-4. 